\title{
O método de instrução ao sósia como subsídio para intervenção e formação de professores no Circolo Italiano San Paolo: uma pesquisa exploratória
}

Luciana Duarte Baraldi

Universidade de São Paulo

lucianabaraldi@gmail.com

RESUMO: Este artigo tem por objetivo apresentar uma experiência de intervenção em situação de trabalho docente baseada no método de instrução ao sósia, elaborado por Ivar Oddone - médico, psicólogo e militante político italiano que figurou como um dos líderes do Modelo Operário Italiano (MOI) de luta para a saúde do trabalhador nos locais de trabalho - e seu grupo (1981, 1986) no contexto de formação continuada dos trabalhadores da Fiat nos anos 1970, tendo inspirado empreendimentos no campo da saúde do trabalhador no Brasil a partir da década de 1980. Esse método foi reinterpretado por Clot na Clínica da Atividade (1999, 2001, 2006, 2017) com o intento de produzir conhecimentos para a ação e promover transformações em outros contextos laborais. A intervenção foi realizada com duas docentes de língua italiana do Circolo Italiano San Paolo e, posteriormente, transformada em uma pesquisa exploratória (GIL, 2008). Nossa proposta é comentar os referenciais teóricos, descrever o contexto de intervenção e as etapas a partir das quais os dados coletados foram analisados à luz das teorias que fundamentam a pesquisa derivada da intervenção e, por fim, apresentar as conclusões acerca da importância da instrução ao sósia, no referido contexto, para a formação de um coletivo e a ampliação do poder de agir (CLOT, 2010) das docentes.

Palavras-chave: Instrução ao sósia. Intervenção. Trabalho docente. Formação de professores. Italiano como língua estrangeira.

ABSTRACT: Questo articolo si propone di presentare un'esperienza di intervento in una situazione lavorativa didattica basata sul metodo di istruzioni al sosia, elaborata da Ivar Oddone - medico, psicologo e attivista politico italiano che figurava come uno dei leader del Modello Operativo Italiano (MOI) di lotta per la salute dei lavoratori sul luogo di lavoro - e il suo gruppo (1981, 1986) nell'ambito della formazione continua per i lavoratori Fiat negli anni '70, avendo ispirato iniziative nel campo della salute dei lavoratori in Brasile sin dagli anni '80. Questo metodo è stato reinterpretato da Clot presso la Clinica dell'Attività (1999, 2001, 2006, 2017) con l'intenzione di produrre conoscenza per l'azione e promuovere cambiamenti in altri contesti di lavoro. L'intervento è stato realizzato con due insegnanti di lingua italiana del Circolo Italiano San Paolo e, successivamente, si è trasformato in una ricerca esplorativa (GIL, 
2008). La nostra proposta è di commentare il quadro teorico, descrivere il contesto dell'intervento e le fasi a partire dalle quali sono stati analizzati i dati raccolti alla luce delle teorie che stanno alla base della ricerca derivata dall'intervento e, infine, presentare le conclusioni sullimportanza delle istruzioni al sosia, nel contesto della ricerca, per la formazione di un collettivo e l'espansione del potere di azione (CLOT, 2010) delle docenti.

Parole chiavi: Istruzioni al sosia. Intervento. Lavoro docente. Formazione di insegnanti. Italiano lingua straniera.

ABSTRACT: This article aims to present an intervention experience in a teaching work situation based on the method of instruction to the double, elaborated by Ivar Oddone - doctor, psychologist and Italian political activist who figured as one of the leaders of the Italian Operative Model (IOM) of struggle for worker's health in the workplace - and his group $(1981,1986)$ in the context of continuing training for Fiat workers in the 1970s, having inspired ventures in the field of worker health in Brazil since the 1980s. This method was reinterpreted by Clot at Clinic of Activity $(1999,2001,2006,2017)$ with the intention of producing knowledge for action and promoting changes in other work contexts. The intervention was carried out with two Italian language Italian teachers from the Circolo Italiano San Paolo and, later, transformed into an exploratory research (GIL, 2008). Our proposal is to comment on the theoretical frameworks, describe the context of intervention and the steps from which the data collected were analyzed in the light of the theories that underlie the research derived from the intervention and, finally, present the conclusions about the importance of instruction to the double, in that context, for the formation of a collective and the expansion of the power of action (CLOT, 2010) of teachers.

Keywords: Instruction to the double. Intervention. Teaching work. Teacher training. Italian as a foreign language.

\section{Introdução}

$\mathcal{N}$ este artigo apresentaremos reflexões sobre a experiência de aplicação do método de instrução ao sósia em intervenção em situação de trabalho com vistas à sua transformação.

A instrução ao sósia é um método que objetiva produzir conhecimentos para a ação, preocupando-se em promover transformações nas condições de trabalho, visando ao bem-estar e à proteção da saúde dos trabalhadores. $\mathrm{O}$ 
ponto de partida para essas transformações é o saber dos trabalhadores, calcado em suas experiências e vivências.

Nosso contexto de atuação para intervenção em situação de trabalho é o da docência, especificamente, o Circolo Italiano San Paolo, espaço de difusão da cultura italiana e do ensino do italiano como língua estrangeira e língua de herança no município de São Paulo. Nesse contexto, realizamos intervenção, que posteriormente se transformou em pesquisa exploratória, junto a duas docentes da instituição. A partir do material coletado, gerado por meio das etapas da aplicação do método de instrução ao sósia, selecionamos os trechos de maior relevância, que revelam pontos em comum ou de divergência com relação tanto ao trabalho realizado pelas docentes quanto ao que está por trás dele - prescrições e autoprescrições, concepções de língua, de ensino e de aprendizagem.

$\mathrm{Na}$ primeira parte do artigo será descrito e discutido o aporte teórico que orientou a intervenção, acompanhado da descrição do contexto e das etapas de intervenção. Em seguida, nos deteremos a analisar os excertos mais relevantes do material coletado e, por fim, teceremos nossas considerações acerca desta experiência de intervenção que, por fim, deu subsídios à condução de uma pesquisa exploratória.

\section{Pressupostos teóricos}

Este estudo está baseado nos pressupostos do método de intervenção em situações de trabalho denominado instrução ao sósia (IS), desenvolvido por Ivar Oddone (1923-2011), médico, psicólogo e militante político italiano influenciado pelo trabalho de Antonio Gramsci, figurando como um dos líderes do Modelo Operário Italiano (MOI) de luta para a Saúde do Trabalhador nos locais de trabalho. Esse método de intervenção surgiu no contexto de formação de trabalhadores da Fiat na década de 1970 (ODDONE et al, 1981), tendo, a 
partir da década de 1980, inspirado empreendimentos no campo da saúde do trabalhador no Brasil.

Botechia e Athayde (2008, p. 57-58) comentam que, no referido contexto, grupos de trabalhadores solicitaram a Oddone informações sobre os riscos que as condições de trabalho poderiam representar para a saúde, com o objetivo de que essas informações fornecessem subsídios à luta pelas mudanças nas condições de trabalho consideradas nocivas. Oddone e seu grupo hipotetizaram que os trabalhadores desenvolvem competência profissional, porém normalmente não têm condições de transmitir sua experiência, sua competência. Assim, iniciou-se a busca de Oddone e seu grupo por meios e condições que pudessem favorecer a transmissão da experiência do trabalhador e da formalização dessa experiência, a partir do entendimento de que os trabalhadores podem produzir conhecimento por meio dela.

Ainda segundo Botechia e Athayde (2008, p. 59), no contexto da formação de trabalhadores da Fiat, os pesquisadores, impedidos de ter acesso direto às instalações da fábrica, criaram uma alternativa original a essa dificuldade imposta: uma modalidade de confrontação denominada instrução ao sósia (istruzioni al sosia - em italiano, no plural: instruções ao sósia).

A instrução ao sósia é um suporte metodológico que tem como objetivo gerar conhecimentos para a ação, preocupando-se em promover transformações nas condições de trabalho, visando ao bem-estar e à proteção da saúde dos trabalhadores. Tais transformações podem ser promovidas a partir do saber dos trabalhadores - suas experiências e vivências -, tomando-se como ponto de partida o fato de que o trabalhador é um "sujeito rico de uma experiência que o especialista não possui" (MUNIZ et al, 2013, p. 285). Enquanto suporte metodológico, a instrução ao sósia permite pôr em evidência o plano que organiza as ações do trabalhador ao defrontar-se com os problemas que vive na concretude do trabalho que realiza, explicitando-os, socializando- 
os e discutindo-os. O plano que organiza suas ações está ligado a uma experiência coletiva, a um patrimônio comum, compartilhado por pares, isso porque o saber individual de cada trabalhador é validado por grupos homogêneos formados por trabalhadores que não apenas atuam em um mesmo ambiente físico e social, mas que também têm interesses em comum, o que revela a importância da formação de um coletivo de trabalho.

Vale lembrar que, dentro dessa perspectiva, o coletivo de trabalho não é sinônimo de coleção de pessoas, pois, para que o coletivo se forme é necessário que os sujeitos envolvidos estejam realmente dispostos a fazer parte de um grupo que se debruce sobre os conflitos e as controvérsias do trabalho que realizam. Assim, nas palavras de Clot (2006, p. 102; 104), "o coletivo não é uma coleção, é o contrário da coleção. O coletivo, nesse sentido, é entendido como recurso para o desenvolvimento individual. [...] É a profissão como história comum, do gesto partilhado a ser transmitido por herança como história coletiva do pensar sobre o trabalho.”. Daí a importância, nessa perspectiva, do coletivo de trabalho, pois ele é será o instrumento por meio do qual os conflitos virão à tona, serão discutidos e poderão ser transformados.

O método da instrução ao sósia é, portanto, um dispositivo que ajuda a pôr em evidência questões ligadas aos problemas enfrentados ao realizar o trabalho em si, à relação com os colegas e com superiores e hierarquias em geral, assim como ao movimento sindical (levando-se em consideração que o método foi criado em contexto fabril). É por meio desse suporte metodológico que o trabalhador pode realizar a crítica ao plano de trabalho e promover sua transformação.

$\mathrm{Na}$ instrução ao sósia, o trabalhador fala sobre sua atividade projetando-a em um futuro hipotético; "fazendo de conta" que outro trabalhador será seu sósia (seu clone) e que o substituirá em seu trabalho. Dentro dessa metodologia, esse trabalhador pode ser chamado de trabalhador-instrutor. 
O trabalhador que fará o papel de interveniente (intervenant), trabalhadorsósia, dá início à aplicação do método por meio da seguinte pergunta ao trabalhador-instrutor:

\begin{abstract}
Se existisse outra pessoa perfeitamente idêntica a você do ponto de vista físico, como você o instruiria para se comportar na fábrica com relação às tarefas, aos seus colegas de trabalho, à hierarquia e à organização sindical (ou outras formas organizativas) de forma que ninguém perceba que se trata de outro e não de você?'1 (ODDONE, RE e BRIANTE, 1981, p. 57) apud Muniz et al (2013, p. 288)
\end{abstract}

As perguntas que derivam dessa instrução inicial devem ser feitas pelo trabalhador-sósia empregando a primeira pessoa do singular ("eu") e as questões colocadas ao trabalhador-instrutor devem estar baseadas no como ele faz; jamais no porquê, pois o que se deseja acessar é o real do trabalho (trabalho realizado - no caso da metodologia de instrução ao sósia, o trabalho projetado), e não as prescrições e as regras a que o trabalhador está exposto, ultrapassando o fato de que ele, muitas vezes, tende a falar sobre seu trabalho de um ponto de vista idealizado, reproduzindo um "manual prescritivo" de como se deve trabalhar, sem deixar vir à tona todas as contradições, os conflitos e o desconforto causados pela distância entre o trabalho prescrito e o trabalho efetivamente realizado. Assim, o objetivo, conforme nos explicam Botechia e Athayde (2008, p. 61), é "aumentar o conhecimento do trabalhador sobre o seu próprio trabalho, explicitando aquilo que já se tornou um hábito, aquilo que é óbvio, e, por outro lado, evidenciando o caráter inventivo e enigmático da atividade de trabalho", de forma que desenvolvam a capacidade de compreender para transformar. A orientação deve ser dada pelo trabalhadorinstrutor empregando a segunda pessoa do singular ("tu" ou "você"), com o objetivo de que, ao elaborar verbalmente as instruções detalhadas a seu sósia, o

\footnotetext{
1 Se ci fosse un'altra persona perfettamente uguale a te dal punto di vista fisico, come gli diresti di comportarsi in fabbrica rispetto alla mansione, ai compagni di lavoro, alla gerarchia aziendale, all'organizzazione sindacale (o ad altre organizzazioni dei lavoratori), in modo tale che non fosse possibile accorgersi che non sei tu? (ODDONE, RE e BRIANTE, 2008, p. 96).
} 
trabalhador "saia de si" por um momento, olhando para seu trabalho como um observador externo, como um sujeito observador de sua própria atividade. Trata-se de uma tarefa difícil, porque normalmente não falamos do trabalho em si, mas da rotina que o envolve. Assim como outras técnicas de coanálise do trabalho (autoconfrontação e aloconfrontação - desenvolvidas na França, na década de 1990, pelo linguista Daniel Faïta - Faïta e Vieira, 2003), a instrução ao sósia possibilita, então, que o trabalhador confronte seus planos para agir e seja crítico com relação a tais planos, transformando-os por meio do aperfeiçoamento de estratégias de intervenção sobre as situações de trabalho. Isso porque esses métodos de intervenção procuram colocar os sujeitos e sua atividade em movimento, por meio da verbalização das atividades, com vistas a reorganizá-las e modificá-las.

Nessa dinâmica de aplicação do método, o papel do trabalhador-instrutor será dar instruções para a substituição e responder às perguntas do trabalhadorsósia, enquanto o papel deste como interveniente deverá ser o de fazer perguntas, exigindo instruções o mais detalhadas possível, levando o trabalhador-instrutor a entrar nas minúcias, introduzindo elementos de variabilidade e dando relevo às nuances impressas por cada trabalhador ao realizar suas tarefas e ao estabelecer relações com os meios de trabalho, os colegas e a hierarquia, deslocando-o de seu lugar naturalizado. Nas palavras de Muniz et al (2013, p. 288), a instrução ao sósia é uma estratégia que "permite reconhecer que já existe uma 'psicologia não escrita' construída na e pela atividade dos trabalhadores", ideia que retomam de Oddone. Clot (2006, p. 100) comenta que essa é "uma psicologia do trabalho não escrita, informal, que pode ser a fonte para o desenvolvimento da psicologia do trabalho escrita".

O método de instrução ao sósia não permite recolher o comportamento real e total do indivíduo, mas a representação que ele faz do próprio comportamento, por meio da verbalização que faz acerca do seu trabalho, 
tratando-se de uma forma de externalizá-lo, de transformar suas ações em linguagem. Oddone, Re e Briante (1984, p. 57) apud Muniz et al (2013) destacam que "é evidente que com este método não é o comportamento real e total do indivíduo que recolhemos, mas a sua imagem, o seu duplicado, isto é, a representação que ele faz do seu próprio comportamento".

Se quisermos aprender o trabalho, precisamos nos debruçar sobre ele e discutir seus conflitos e suas controvérsias. Para acessarmos o trabalho realizado, podemos usar o registro/gravação do que o trabalhador faz ou fala sobre seu trabalho. Assim, na instrução ao sósia, o áudio da discussão é levado para casa pelo(s) trabalhador(es)-instrutor(es), que o ouve(m) e elabora(m) um texto-comentário que discuta algum ponto que lhe(s) chamou atenção e/ou lhe(s) causou algum estranhamento. Em um encontro seguinte, denominado retorno ao coletivo, faz-se a leitura do(s) texto(s)-comentário e todos os trabalhadores participantes discutem os pontos escolhidos. O objetivo dessa fase é tornar a transformação da situação de trabalho algo compartilhado e durável, isto é, que as transformações sejam realmente duradouras no contexto em que elas se apresentarem.

Como efeitos da aplicação do método da instrução ao sósia, destacam-se: a conscientização do trabalhador sobre a complexidade do trabalho e sua dimensão subjetiva, seu distanciamento em relação à própria atividade, a visualização de novas maneiras de agir em situações específicas, a comparação entre diferentes maneiras de agir, a avaliação dos efeitos de cada escolha estratégica, o ganho em saúde do trabalhador e a ampliação de seu poder de agir no trabalho. Como nos recordam Muniz et al (2013, p. 289), "“...] a luta pela saúde não se faz apenas com a denúncia dos adoecimentos e acidentes produzidos nas situações de trabalho, mas também pela ampliação da capacidade de intervenção no seu trabalho". 
Lousada (2017, p. 96) esclarece que após a instrução ao sósia ser usada para a formação de trabalhadores da indústria, "ela foi retomada e desenvolvida por Clot (1999) como um método indireto para fazer com que o trabalhador (de qualquer categoria) reflita sobre sua atividade de trabalho ao projetá-la a um futuro hipotético". Assim, no âmbito que nos interessa particularmente - a didática de línguas estrangeiras/de herança e a formação do professor que atua nesse contexto -, a instrução ao sósia procura atentar-se a algumas questões: como pôr em prática as prescrições (da política, do sistema de ensino, da instituição de ensino, da coordenação pedagógica, da didática das línguas etc.); como responder às demandas das várias instâncias sociais requeridas pela variedade e variabilidade dos contextos em que esse trabalhador atua. Portanto, o método de instrução ao sósia constitui-se, para a docência, em uma possibilidade de formação em serviço, por se tratar de um método que busca pôr os sujeitos e sua atividade em movimento, caracterizando-se como uma atividade formativa.

$\mathrm{Na}$ seção a seguir procuraremos descrever a intervenção realizada por meio da aplicação do método de instrução ao sósia com duas docentes de italiano de uma instituição de ensino no primeiro semestre de 2019. As reflexões e os resultados obtidos por meio dessa intervenção nos deram subsídios que possibilitaram discutir essa experiência de uma perspectiva baseada em um aporte de pesquisa exploratória.

\section{2. $O$ contexto de intervenção e suas etapas}

A intervenção realizada, resultou, em um segundo momento, em uma pesquisa que pode ser considerada uma pesquisa exploratória, definida por Gil (2008: 28) como uma modalidade de pesquisa aplicada cuja finalidade é "desenvolver, esclarecer e modificar conceitos e ideias, tendo em vista a formulação de problemas mais precisos ou hipóteses pesquisáveis para estudos 
O método de instrução ao sósia como subsídio para intervenção e formação de professores no Circolo Italiano San Paolo: uma pesquisa exploratória

Luciana Duarte Baraldi

posteriores". Segundo Gerhardt e Silveira (2009, p. 35), Gil destaca que pesquisas exploratórias são desenvolvidas objetivando proporcionar uma visão geral acerca de um fato, maior familiaridade com o problema, de forma que ele se torne mais explícito ou proporcione a construção de hipóteses. $\mathrm{O}$ autor comenta ainda que não raro esse tipo de pesquisa constitui a etapa inicial de uma investigação mais ampla. Assim, muitas vezes, o produto final de uma pesquisa exploratória configura-se como um "problema mais esclarecido, passível de investigação mediante procedimentos mais sistematizados" (GIL, 2008, p. 28).

Nosso contato com o método de instrução ao sósia e com outros métodos indiretos adotados pela Clínica da Atividade (Clot) nos deu subsídios para pôr em prática as teorias estudadas por meio de uma intervenção realizada em um curto período - durante o mês de junho de 2019 - com duas docentes de língua italiana que atuam no Circolo Italiano San Paolo, mesmo local de trabalho da interveniente. Assim, concluímos que intervenção aqui descrita se enquadra como pesquisa exploratória pelo fato de ser um primeiro exercício de prática e reflexão baseada nos referenciais teóricos apresentados na seção anterior.

Ambas as docentes participantes da intervenção trabalham no Circolo Italiano desde o início de 2019, lecionavam, na ocasião para turmas iniciantes A1, conforme Quadro Comum Europeu de Referência para Línguas (CEFR) e utilizam em suas aulas o livro didático Nuovo contatto A1 (BOZZONE COSTA; GHEZZI; PIANTONI, 2014), material adotado pela instituição como base para os cursos oferecidos. A interveniente atua na instituição desde agosto de 2018, lecionando para grupos principiantes (A1) e intermediários (B1) que adotam o mesmo material já mencionado.

A docente J é doutora em Literatura Italiana pelo programa de pósgraduação em Língua, Literatura e Cultura Italianas do Departamento de Letras Modernas da Faculdade de Filosofia, Ciências e Letras da Universidade de São 
Paulo (DLM-FFLCH-USP), tendo obtido seu título em dupla titulação com a Università degli Studi di Firenze (UniFi), e atua há 10 anos como professora de italiano.

A docente L é mestra em Língua Italiana pelo programa de pós-graduação em Língua, Literatura e Cultura Italianas do Departamento de Letras Modernas da Faculdade de Filosofia, Ciências e Letras da Universidade de São Paulo (DLM-FFLCH-USP) e atua há 4 anos como professora de italiano.

Após a proposição da intervenção no referido contexto e do aceite das professoras J e L, foi possível formar esse pequeno coletivo ${ }^{2}$. $\mathrm{Na}$ etapa seguinte, lhes foi apresentado o referencial teórico que nortearia a intervenção - os pressupostos do Modelo Operário Italiano e a instrução ao sósia, método de intervenção em situações de trabalho realizado com cada uma das docentes por meio de entrevistas individuais, as quais tinham como ponto de partida a seguinte orientação dada pela interveniente, derivada da orientação construída por Oddone, Re e Briante: "Suponhamos que eu seja sua sósia e que amanhã eu deva te substituir em seu trabalho. Quais são as instruções que você deveria me dar para que ninguém perceba a substituição?” (CLOT, 2001, p. 9).

Os dados gerados foram registrados em áudio, totalizando aproximadamente 64 minutos, e, posteriormente, transcritos. Tanto o registro em áudio quanto sua transcrição foram compartilhados com as docentes, para que, a partir desses registros, somados à própria experiência de dar instruções a um suposto sósia, elas pudessem analisar o que disseram sobre suas práticas e refletir sobre as questões que mais lhes chamaram atenção em suas falas. Em seguida, foi realizado um encontro de retorno ao coletivo, em que ambas as docentes, assim como a interveniente, puderam destacar trechos do material

\footnotetext{
2 Agradecemos às docentes $\mathrm{J}$ e L pela disposição e pelo interesse em participar dessa intervenção, assim como à gerente e coordenadora pedagógica do Circolo Italiano San Paolo por todo apoio concedido, tendo disponibilizado inclusive as dependências da instituição para que as etapas da intervenção pudessem ser realizadas.
} 
transcrito e realizar coletivamente a discussão sobre as questões que se revelaram pontos de controvérsia. Assim como na fase da instrução ao sósia, os dados gerados na etapa de retorno ao coletivo também foram gravados em áudio, transcritos e compartilhados com as docentes, que, a partir dos materiais produzidos e da experiência vivenciada, foram convidadas a produzir uma reflexão final, que denominamos relato sobre a experiência, no qual pudessem discorrer livremente acerca da experiência de intervenção de que foram participantes. As etapas da intervenção estão sintetizadas no quadro a seguir:

\begin{tabular}{|l|l|}
\hline Fase & \multicolumn{1}{c|}{ Etapa da intervenção } \\
\hline 1 & $\begin{array}{c}\text { Convite a alguns professores do Circolo Italiano à participação da } \\
\text { intervenção/formação de coletivo. }\end{array}$ \\
\hline 2 & $\begin{array}{c}\text { Apresentação do referencial teórico às docentes que se dispuseram a } \\
\text { participar da intervenção. }\end{array}$ \\
\hline 3 & $\begin{array}{l}\text { Realização da instrução ao sósia com as docentes participantes } \\
\text { individualmente (interveniente-docente). Envio dos registros em áudio às } \\
\text { docentes. }\end{array}$ \\
\hline 4 & $\begin{array}{l}\text { Envio da transcrição do registro em áudio da instrução ao sósia às } \\
\text { docentes. }\end{array}$ \\
\hline 5 & $\begin{array}{l}\text { Realização do retorno ao coletivo (docentes-interveniente/ docente- } \\
\text { docente). Envio do registro em áudio às docentes. }\end{array}$ \\
\hline 6 & $\begin{array}{l}\text { Envio da transcrição do registro em áudio do retorno ao coletivo às } \\
\text { docentes. }\end{array}$ \\
\hline 7 & $\begin{array}{c}\text { Entrega do relato sobre a experiência (escrito) produzido por cada } \\
\text { docente. }\end{array}$ \\
\hline
\end{tabular}

A partir do material coletado, selecionamos os trechos de maior relevância, seja pelo estranhamento que causaram nas docentes e na interveniente e, por isso, funcionaram como motores de questionamentos e reflexões, seja aqueles que revelam pontos em comum ou de divergência com relação tanto ao trabalho realizado pelas docentes quanto ao que está por trás dele - prescrições e autoprescrições, concepções de língua, de ensino e de aprendizagem.

$\mathrm{Na}$ próxima seção procederemos à análise e discussão dos dados selecionados, para posterior encaminhamentos às considerações finais. 


\section{Análise dos dados}

\subsection{Instrução ao sósia}

Com relação ao entendimento da realização da instrução ao sósia, ambas as docentes compreenderam a dinâmica do método e conseguiram dar as instruções solicitadas pela interveniente. Entretanto, parece-nos importante destacar que ambas tiveram dificuldades de dar as instruções usando a segunda pessoa do singular ("tu" ou "você"), o que era esperado nessa intervenção, primeiramente pelo fato de esse ter sido o contato inicial das docentes participantes com o método. Ao mesmo tempo, essa dificuldade revela a complexidade de realizar o ato de nos distanciarmos, enquanto trabalhadoresdocentes, de nosso agir profissional. A verbalização requerida por métodos indiretos como a instrução ao sósia exige do trabalhador-instrutor um deslocamento de si mesmo que se materializa no e por meio do seu discurso. A dificuldade enfrentada pelas docentes indica que esse distanciamento exigido pelo método é um fator que se impõe, de início, como algo desafiador, sendo superado no decorrer da instrução.

$\mathrm{Na}$ etapa da instrução ao sósia, durante as orientações para o trabalho hipotético da sósia referente ao andamento da atividade iniciada na aula anterior, quando questionada sobre o uso da língua materna em sala de aula, a docente J mostra uma preocupação muito grande com a presença de português em sala de aula, deixando transparecer em diversos momentos de sua fala uma voz da interdição:

Sósia: E aí eu faço essa pergunta pra eles, eu tenho que falar em português ou em italiano?

Docente J: Não, tudo em italiano, a gente não fala nada em português, nenbuma palavra em português.

S: Em nenhum momento se fala o português, não posso falar?

$\mathrm{J}$ : Eu raramente uso o português, raramente uso, é muito, muito raro mesmo, eu usar o português... Eles falam o português, apesar de en forçá-los a falar em italiano, forçá-los entre aspas, numa leitura, fazer com que eles falem, pratiquem a língua, raramente eu falo, muito raro mesmo, então se vocêp puder evitar, melhor.

$[\ldots]$ 
S: E se eventualmente eles não entenderem, eu posso explicar, eu posso usar português ou não?

J: Eu gostaria que você evitasse, porque, é pra força-los, porque se não, eles vão se acomodar e vão recorrer, vão querer recorrer sempre ao português. Não, claro, se você percebe que, de todas as estratégias que você está utilizando, nenhuma delas adianta e que isso está prejudicando o entendimento do exercício, aí sim, você pode recorrer ao português, mas eu aconselho que você não faça isso, evite ao máximo, aconselho evitar ao máximo. (grifos nossos)

No excerto selecionado, nota-se o emprego recorrente do verbo evitar, do advérbio raramente relacionado ao uso do português, assim como os pronomes indefinidos nada e nenbum, ambos significando nulo, inexistente.

Em um momento seguinte da entrevista de instrução ao sósia, a docente J passa a dar orientações sobre como apresentar o tempo verbal passato prossimo (passado composto) aos alunos:

S: E aí quando eu terminar esse exercício, o que eu tenho que fazer depois?

J: Aí vai começar a parte do passato prossimo.

S: Tá...

J: Passato prossimo, você deve começar de uma maneira bem tranquila porque como é bastante diferente do português, tendo os verbos auxiliares, então a gente tem que fazer de uma maneira que eles não se assustem, porque, geralmente pelo que eu já observei e você também vai observar lá na sala de aula, quando a gente fala que o passado é feito com verbo auxiliar, que são dois verbos auxiliares diferentes, eles ficam um pouco assustados, então é mostrar de uma maneira natural e simples, assim, pra que eles entendam e como é que a gente pode fazer isso? Mostrando por exemplo... usando a gramática, já com os exemplos, mostrando que ah, quando é verbo, por exemplo, de estado, mudança de estado, a gente sempre usa essere porque fala mais sobre a pessoa em si, e tal, essa é a explicação, pra que eles possam entender verbi riflessivi, por exemplo. [...]

Nesse trecho, J mostra conhecimento da estrutura do tempo verbal e preocupação em deixar claro à sua sósia que é importante introduzir esse conteúdo de maneira a não assustar os alunos com as particularidades da estrutura e do uso do tempo verbal em questão. A docente propõe inclusive um passo a passo de como a sósia deveria apresentar esse novo conteúdo, de forma progressiva, primeiramente comentando o uso, dando exemplos práticos em que o passato prossimo apareça e, depois, explicitando os casos em que o auxiliar essere é usado. Essa atitude mostra sua familiaridade com o conteúdo e parece revelar que a docente tem experiência em ensiná-lo, tendo encontrado formas 
de apresentá-lo aos discentes sem que se assustem com as regras subjacentes a ele.

Durante toda a instrução ao sósia, notamos que a docente se concentrou em comentar aspectos relacionados à aplicação do conteúdo a ser ensinado, dando menos importância a aspectos relacionados à gestão da classe e das relações entre alunos, aluno(s)-professor/professor-aluno(s).

$\mathrm{Na}$ instrução ao sósia da professora L, quando perguntada sobre o uso da língua materna durante as aulas de italiano, assim como a docente J, L responde que raramente fala em português, mas explica o motivo: ela sente dificuldade de alternar as duas línguas durante a aula. Diferentemente da professora J, a ausência do português durante as aulas de L não ocorre por um agir profissional baseado em veto à língua materna:

Docente L: Eu raramente falo em português, só quando eles pedem mesmo, que não entendem ou quando é uma tradução assim, pra ganhar tempo, ao invés de dar uma volta falando em italiano, falo direto em português, pra tradução mesmo.

Sósia: Mas eu não devo nunca falar em português?

L: Não é uma restrição, mas eu não consigo ir e voltar do italiano para o português. Então, quando eu preciso falar em português, eu preciso dar uma respirada e pensar em português de novo, eu não consigo por exemplo fazer uma aula bilíngue, em português e em italiano traduzindo tudo, é muito difícil pra mim, então eu falo tudo em italiano porque eu entro aqui pensando em italiano, então é difícil voltar. [...]

Ao contrário do que vimos com a docente J, L demonstra uma preocupação maior em falar sobre questões relacionadas à gestão da sala de aula e ao bem-estar dos alunos. Isso fica evidente ao longo de toda a entrevista de instrução ao sósia, mas selecionamos dois momentos que exemplificam bem. O primeiro está relacionado a uma preocupação com os horários de início e fim da aula, motivada pelo rigor dos alunos:

Docente L: É bom você se programar para chegar meia hora antes, você vem de metrô, que é o mais perto. É bom chegar meia hora antes, porque tem sempre uma questão da chave, de abrir a porta e às vezes, normalmente, a porta está trancada, a gente não sabe onde está a chave, então, pra aula não começar muito tarde, porque alguns alunos são muito rigorosos com horários, quando tá terminando a aula e você propõe um 
exercício que você sabe que vai terminar no tempo, eles falam "Não vai dar tempo", então horário é muito importante. [...]

O segundo momento diz respeito à adoção do que a docente chama de "um objeto de afeto, um objeto didático", que L usa por diversos motivos, entre eles, relaxar os alunos, evitar expô-los quando cometem erros, projetar as falhas da própria docente nesse objeto didático:

L: (...) a Madalena é uma ovelha de pelúcia...

S: Então eu tenho que usar a Madalena, mas eu tenho que fazer o quê exatamente com a Madalena?

L: Você põe ela na mesa, porque quando eu começo com uma turma nova, eu explico que eu tenho uma ajudante, não falo que é um objeto, eu faço eles acreditarem que é uma pessoa, que eu tenho uma ajudante e ela me ajuda a perceber quando os alunos querem que eu fale em português, quando eu repito a explicação, quando eles estão com alguma dúvida que estão com vergonha de perguntar, então aquilo que eu percebo na expressão dos alunos, no silêncio, nas sutilezas assim, eu projeto nela, nessa Madalena, e depois quando eu mostro que é uma ovelha de pelúcia, eles ficam relaxados, porque cria aquela coisa de "Nossa vai ter alguém me observando", mas no final de contas não é. [...]

S: Então eu tenho que colocar em cima da mesa e tem que colocar ela olhando em direção a onde?

L: Muda, ela costuma ficar virada para os alunos ou se, por exemplo, eu escrevo alguma coisa que faltou uma doppia e o aluno percebe, eu também projeto minhas falhas nela, eu falo: "Ai, a Madalena não estava olhando", aí eu viro ela pra lousa, ou dependendo da aula, os próprios alunos interagem e pegam ela e põem na carteira deles, se alguém falta, eles põem no lugar de quem faltou, então ela serve muito pra relaxar a classe, assim, eu percebo que as turmas que entendem como ela funciona, são mais participativas, mais colaborativas. [...]

Com relação à gramática, L também se mostra preocupada em tornar o conteúdo mais palatável aos estudantes, e dá especial atenção ao estilo de aprendizagem de cada aluno, o que pode nos levar a crer que a docente é bastante observadora e atenta às diferenças e necessidades dos discentes.

L: Sim, o conteúdo gramatical aparece, mas ele aparece quase no final da aula porque os alunos já viram aquele conteúdo que eu vou trabalhar, depois tem uma parte de lessico para eles sentirem que conseguem se expressar e o conteúdo gramatical, ele segue um pouco a orientação do livro, um pouco o meu uso, que eu explico o que vai acontecer ali a partir das instruções do livro, do resumo das atividades, mas eu gosto sempre de ir construindo com eles a lógica da coisa, ao invés de falar: "Olha, é assim que funciona", por exemplo, na próxima aula eles vão ver os verbos irregulares, então ao invés de explicar pra eles o que significa um verbo irregular, eu prefiro expor, mostrar alguns verbos e a partir dali, saber o que eles conseguem entender [...] quando eu explico, principalmente gramática, eu uso muita caneta colorida, para cada parte da palavra eu uso 
uma cor, eu explico o que aquela cor significa, porque eu sou muito visual então eu preciso explicar as coisas de modo visual também. Às vezes eu tento buscar associações por exemplo, formal e informal, eu falo que o informal é o polegar, quando se fala em uma situação mais informal, então você usa o "i", com tu e com Lei se estende a mão, então eu desenho a letra "a" na minha mão e mostro alguma coisa assim. Eu tento usar vários recursos assim, no visual, me mexer, ou som, porque eu sei que tem alguns mais visuais e tem alguns que são mais sinestésicos, então eu tento sempre pegar um pouquinho do raciocínio de cada um, na hora de explicar gramática principalmente. [...]

Assim, concluímos que o agir profissional de L está centrado nos alunos, que se tornam o fio condutor de suas aulas e guiam seus gestos profissionais.

\subsection{Retorno ao coletivo}

$\mathrm{Na}$ etapa de retorno ao coletivo, as docentes puderam trazer à discussão alguns pontos que lhes causaram estranhamento ou atenção. J relata ter se incomodado com o tom impositivo de sua orientação com relação à presença/ausência da língua materna durante as aulas de italiano. No trecho destacado, a docente deixa clara a sua tomada de consciência em relação a esse ponto, questionando-se, durante a sua fala, sobre seu agir:

J: [...] uma coisa que me chamou bastante atenção foi o fato da imposição, né? Uma coisa assim de... mesmo explicando pra vocês assim de forçá-los, forçar os alunos entre aspas, na verdade eu acho que é uma postura muito impositiva, né? [...] de uma maneira ou de outra e eu ouvindo esses "forçálos", que eu ouvi várias vezes, forçá-los, forçá-los, forçá-los, forçá-los, então quer dizer talvez que a minha postura seja muito impositiva na sala de aula, talvez... Até hoje, nenhum aluno reclamou diretamente, né? Nenhum aluno falou, assim de uma maneira incisiva, mas isso foi uma coisa que me chamou bastante atenção [...].

Com relação ao comentário feito durante a instrução ao sósia de que os alunos principiantes certamente recorrem ao português, a docente também põe sua atitude em perspectiva e questiona-se sobre a possibilidade de recorrer a outras estratégias para que os estudantes passem a falar em italiano:

J: [...] Eu já parto do suposto que eles não vão conseguir fazer determinada atividade, se esse eu/acho que esse pré-julgamento o momento da minha parte... Não que os afete, porque isso é um pensamento meu que eu expus aqui, né? Eh... Mas talvez... Isso faça com que eu não recorra a outras estratégias para que eles desenvolvam melhor... porque como eu já espero que eles vão falar em português, entendeu? Faz com que eu não recorra a outras estratégias que os façam falar em italiano. [...] 
A docente L comenta a reflexão feita por J acerca do veto ao uso de língua materna nas aulas destacando que essa interdição é proveniente de prescrições que fizeram parte de nossa formação enquanto docentes, as quais, quando incorporadas à nossa prática, se tornam autoprescrições adotadas. No mesmo excerto, L compartilha os critérios que utiliza para o emprego do português durante as aulas. O mais interessante é que, ao final dessa reflexão realizada pelo coletivo, J se apropria da prática de L, reconhecendo nela a estratégia de que precisava para lidar melhor com o emprego do português em sala pelos alunos:

L: [...] eu trabalho muito com análise do discurso, então eu vejo muita transcrição de aula, que é muito comum o professor falar, ele não fala em português na aula, não permito que o aluno fale em português na aula, mas quando você olha a transcrição está cheio de português... Então, às vezes é uma coisa muito da nossa formação de falar: "Não pode falar em português, não pode, não pode...", mas na aula isso acontece, então eu tenho critérios, assim pra usar o português, se o aluno não entende uma palavra, eu traduzo, a não ser que seja alguma coisa que ele já viu, o que os alunos já viram, ou eu falo: "Olha, está na página tal" em italiano, ou eu falo: "Lembra quando a gente estava falando...", eu tento retomar, mas se ele não viu aquilo, eu deixo ele falar em português, porque eu enxergo o português como um... um apoio, então ele pisa no português pra chegar no italiano e eu vejo isso acontecendo nas aulas, assim, eles usarem às vezes o espanhol quando eles estão tentando falar o italiano, então eu prefiro que eles misturem um pouco as línguas, mas falem, do que ficar naquilo: "Ah, mas eu tenho que falar italiano, mas eu não sei me expressar exatamente, então eu vou ficar quieto.", porque pra mim, eu vejo um limite muito fino entre o "Eu não vou falar porque eu não sei falar tudo em italiano" e aí eu vou querer usar o português e usar o português de um apoio para o italiano, então, meu critério normalmente é se eles já viram aquilo, se está em uma atividade que eles têm que falar o italiano, eu peço, mas se é, por exemplo, pra explicar pro colega alguma coisa, ou pra tirar alguma dúvida, e eu vejo que eles ainda não têm/ainda não viram aquilo em italiano, eu deixo usar o português, sem problema.

S: Tá... É uma estratégia interessante, né, essa de tentar, de repente, ver em qual situação pode abrir uma exceção, eu nunca tinha pensado nisso de... de... usar esse critério especificamente, né? De por exemplo: "Ah, essa palavra a gente já viu, já estudou, então não precisa..."

L: Essa estrutura eles já viram, já usaram isso, então...

S: Pode ser um bom momento, inclusive pra alguma retomada, né?

L: Sim...

S: Eu nunca pensei por esse viés, assim...

$\mathrm{J}$ : Inclusive, talvez se a gente pedir pra eles explicarem em português o que eles entenderam, né?

L: Uhum...

J: Por exemplo, explica pra mim o passato prossimo em português, então...

S: Pode ser um caminho... [...] 
A professora L é questionada pela interveniente-sósia sobre as possíveis motivações para a predominância de uma postura lúdica em sua alunas (Madalena, o objeto didático-afetivo, por exemplo), e responde afirmando que:

L: Vem muito do meu jeito de estudar, de aprender, então eu preciso criar outros mecanismos, além de só ler e fazer exercícios, então, por exemplo, pro passato prossimo, ou para as coisas de gramática, eu preciso de cor, eu preciso de desenho, pra eu associar uma coisa com a outra e eu não sei o quanto isso realmente afeta, mas tem muita gente na minha família que tem dislexia, então eu estou acostumada a conviver com associações completamente fora da caixinha e pra mim é mais fácil fazer associação quase besta, assim, de desenhar uma coisa na minha mão, porque $o$ espanto daquilo é o que me faz guardar, se eu criar uma música, uma regra, desenhar uma coisa, trocar de cor, andar na sala, fazer os alunos se mexerem, parece que fica mais fácil pra eu explicar do que uma aula frontal, por exemplo, eu não consigo fazer uma aula frontal porque não sai. $[\ldots]$

Essa explicação nos permite entender a origem de alguns gestos profissionais demonstrados pela docente: apesar de propostas lúdicas, esses gestos mostram-se como autoprescrições que, de certa forma, interferem de forma não tanto positiva em uma das turmas em que ela atua. Quando convidada a comentar os trechos da instrução ao sósia que mais lhe causaram estranhamento, L menciona sua aula centrada nos alunos:

L: E eu percebi que eu tenho uma... a minha aula é muito centrada nos alunos, eu dependo muito deles, então se é uma turma tímida, se é uma turma mais objetiva, que responde ali, a resposta que o exercício pede, se é uma turma mais silenciosa, se não tem, como posso dizer? Entrosamento entre os alunos, eu fico totalmente travada na aula porque eu dependo da participação deles pra fazer minha aula. Então... quando é uma turma quieta ou se tem um aluno que está com muita dificuldade, ou que está sofrendo, eu sofro junto e isso acaba me limitando, eu não consigo, por exemplo, fazer uma aula frontal assim, falar "Olha, o assunto é esse" e explicar, eu percebi que isso é uma coisa que me atrapalha, principalmente nas turmas de terça e quinta por que eles são quietos, então, nessa parte de confronto, ou quando eu vou explicar alguma coisa de gramática que eu preciso que eles deduzam o que eles estão entendendo, pra daí eu começar a explicar e eles não falam nada, eu fico completamente perdida, que é uma coisa que eu preciso rever, assim, plano $\mathrm{B}$, se a turma é quieta como que vai ser o funcionamento da minha aula. $[\ldots]$

L: Talvez isso seja por conta... da minha experiência com aula particular, porque sou só eu e o aluno, então, eu quero que o aluno na aula particular fale mais, eles normalmente falam que só tem eles, então, talvez eu carregue isso pra aula em grupos e não tenha percebido. [...] 
A interveniente-sósia sugere a L, com a participação de J, preparar aulas frontais e expositivas para a turma com a qual a docente tem dificuldade de lidar. É a partir da análise dessa sugestão que L reconhece em sua fala o conflito que a desestabiliza - sem a participação dos alunos ela não consegue saber se eles estão aprendendo:

S: E você acha, de repente, no caso dessa turma que é muito silenciosa... o seu estilo de dar aula é mais, assim, participativo, pedindo a colaboração dos alunos, né? Mas por exemplo, você acha que nessa turma, se você tentar dar uma aula mais frontal, você já tentou, assim, alguma coisa parecida? Dar uma aula mais expositiva, mesmo?

J: E depois dar o exercício, pra depois fazer e depois corrigir...

S: É... Pra ver como é que/se muda alguma coisa...

$[\ldots]$

L: Talvez eu sinto que com uma aula frontal eles não estão aprendendo, porque eu não estou ouvindo, sabe? Eu não estou vendo eles raciocinarem...

J questiona L sobre o desempenho dos estudantes analisado durante a correção dos exercícios. Por meio desse questionamento, J mostra a L que, se os estudantes respondem bem aos exercícios, então eles estão aprendendo, o que quer dizer que L está atingindo seu objetivo de fazê-los aprender italiano, mesmo que, especificamente com essa turma mais silenciosa, não consiga verificar por meio da interação durante a aula:

J: Mas depois se você falar pra eles fazerem exercício e você corrigir junto com eles?

L: Eles acertam...

$\mathrm{J}$ : Então eles entenderam... [...]

Assim, a partir das verbalizações de L e J acerca dos conflitos e das controvérsias presentes em suas práticas que, no contexto do coletivo formado, por meio da coanálise, são desencadeadas reflexões que permitem a tomada de consciência desses conflitos e possibilitam novas formas de organização e modificação do agir profissional docente.

No relato escrito da etapa final, J destaca que a experiência de intervenção com instrução ao sósia foi um exercício "diferente e bastante importante para que eu pudesse refletir sobre minha postura em sala de aula e as 
técnicas/estratégias de ensino-aprendizagem que utilizo com meus alunos", porém "na prática torna-se um pouco mais complicado, não pela autoavaliação em si, uma vez que procuro sempre autoavaliar meu trabalho para que eu possa melhorá-lo e evoluir enquanto profissional, mas por ter de enxergar os mínimos detalhes das aulas, de minhas condutas, dos alunos, etc.”. Com relação ao retorno ao coletivo, a docente afirma que propiciou uma "reflexão ainda mais profunda, pois, além de verbalizar minhas ponderações, o que colabora para uma conscientização maior, o ponto de vista das colegas mostrou-me aspectos que não havia levado em consideração e a discussão fez com que pensássemos em alternativas para os problemas levantados.”.

L comenta que, durante a instrução ao sósia, "a experiência de descrever meu trabalho com o máximo de detalhes foi muito interessante, pois durante o momento do relato eu tive a sensação de me deslocar do ambiente da entrevista para reviver minhas ações rotineiras". O retorno ao coletivo lhe possibilitou perceber que "expor as minhas dificuldades e ouvir o ponto de vista das colegas foi muito importante, pois foi muito reconfortante perceber que elas estavam se colocando no meu lugar e encontrando as mesmas dificuldades ou buscando soluções junto comigo".

\section{Considerações finais}

Por meio da análise dos excertos escolhidos pudemos verificar que o método da instrução ao sósia, adotado na intervenção realizada com esse coletivo, possibilitou, em um primeiro momento, que as docentes tomassem consciência das minúcias de seu métier/mestiere, por meio da ação de colocar em palavras seu agir. Falar sobre o trabalho é desafiador, pois dessa verbalização emergem as questões que o envolvem. Entretanto, a experiência de "sair de si" mostra-se um instrumento para olhar para si mesmo. Tal como diz o filósofo do rei em $O$ conto da ilha desconbecida de Saramago, "Se não sais de ti, não chegas 
a saber quem és". Assim, se "todo o homem é uma ilha", faz-se "necessário sair da ilha para ver a ilha, que não nos vemos se não nos saímos de nós".

O retorno ao coletivo pareceu-nos ser o ponto mais importante da intervenção, pois ele representa o momento em que os sujeitos colocam-se nos lugares uns dos outros, de forma não institucionalizada e verdadeiramente empática, abrindo caminho para a identificação de dificuldades comuns e, principalmente, para, juntos, encontrar soluções, construir novas formas de agir. O retorno ao coletivo também nos recorda que o trabalho docente é solitário e o quanto a formação do coletivo tem a potência de ampliar a capacidade de pensar e de agir. Nas palavras de L, "muitas vezes nosso contato maior na escola é com os alunos e não temos esse tempo de conversar e refletir com os colegas. A gente sempre fala em aula que a dúvida do outro pode ser a nossa dúvida também, mas não percebe que isso também pode acontecer entre nós, professores".

A intervenção que possibilitou esta pesquisa exploratória, apesar de breve, permitiu-nos experienciar uma nova perspectiva de formação de professores: aquela que ocorre por meio do exercício de sua prática, distanciando-se das concepções formativas que pretendem difundir novas prescrições e "boas práticas" desconectadas do real da atividade docente.

Desse modo, sugere-se a continuidade da aplicação do método de instrução ao sósia no referido contexto como instrumento para a formação contínua dos docentes e, também, para a continuidade das pesquisas nesse âmbito.

\section{Referências}

BOTECHIA, F; ATHAYDE, M. Conversas sobre o trabalho sob o ponto de vista da atividade: algumas abordagens metodológicas. In: BARROS, M. E. B. de; HECKERT, A. L. C.; MARGOTO, L. (Orgs.) Trabalho e saúde do professor: cartografias no percurso. Belo Horizonte: Autêntica, 2008. 
BOZZONE COSTA, R.; GHEZZI, C.; PIANTONI, M. Nuovo contatto A1: corso di lingua e civiltà italiana per stranieri. Torino: Loescher Editore, 2014.

CLOT, Y. La fonction psycologique du travail. Paris: Presses Universitaires de France, 1999.

Méthodologie em clinique de l'activité: l'exemple du sosie. In: DELEFOSSE, M. S.; ROUAN, G. (Orgs.). Les méthodes qualitatives en psycologie. Paris: Dunod, 2001. p. 125-146.

Trabalho e poder de agir. Tradução de Guilherme João Freitas Teixeira e Marlene Machado Zica Vianna. Belo Horizonte: FabreFactum, 2010.

2017.

. Clínica da Atividade. Horizontes, Itatiba, v. 35, n. 3, p. 18-22, set./dez.

CLOT, Y.; SOARES, D. H.; COUTINHO, M.; NARDI, H. C.; SATO, L. Entrevista: Yves Clot. Cadernos de Psicologia Social do Trabalho, São Paulo, v. 9, n. 2, p. 99-107, 2006.

FAÏTA, D.; VIEIRA, M. Réflexions méthodologiques sur l'autoconfrontation croiseé. DELTA: Documentação em Estudos em Linguística Teórica e Aplicada, São Paulo, v. 19, p. 123-154, 2003.

GERHARDT, T. E.; SILVEIRA, D. T. (Orgs.) Métodos de pesquisa. Porto Alegre: Editora da UFRGS, 2009.

GIL, A. C. Métodos e técnicas de pesquisa social. 6. ed. São Paulo: Atlas, 2008.

LOUSADA, E. G. Intervenção, pesquisa e formação: aprendizagem do trabalho educacional e desenvolvimento de professores. Horizontes, Itatiba, v. 35, n. 3, p. 94-104, set./dez. 2017.

MUNIZ, H. P. et al. Ivar Oddone e sua contribuição para o campo da Saúde do Trabalhador no Brasil. Revista Brasileira de Saúde Ocupacional, São Paulo, v. 38, n. 128, p. 280-291, 2013.

ODDONE, I. et al. Ambiente de trabalho: a luta dos trabalhadores pela saúde. São Paulo: Hucitec, 1986.

ODDONE, I.; RE, A.; BRIANTE, G. Redécouvrir l'expérience ouvrière: vers une autre psycologie du travail? Paris: Éditions Sociales, 1981. 
O método de instrução ao sósia como subsídio para intervenção e formação de professores no Circolo Italiano San Paolo: uma pesquisa exploratória Luciana Duarte Baraldi

ODDONE, I.; RE, A.; BRIANTE, G. Esperienza operaia, coscienza di classe e psicologia del lavoro. Torino: Otto, 2008. E-book. Disponível em: $<$ https://www.diario-prevenzione.it/ebook/Esperienze_operaie_70.pdf>. Acesso em: jul. 2019.

SARAMAgO, J. O conto da ilha desconhecida. São Paulo: Companhia das Letras, 1998. 